\title{
(6) OPEN ACCESS \\ A longitudinal study of well-being, confidence and competence in junior doctors and the impact of emergency medicine placements
}

\author{
Suzanne Mason, ${ }^{1}$ Colin O'Keeffe, ${ }^{1}$ Angela Carter, ${ }^{2}$ Chris Stride $^{2}$
}

\begin{abstract}
- Additional material is published online only. To view please visit the journal online (http://dx.doi.org/10.1136/ emermed-2014-204514).

${ }^{1}$ School of Health and Related Research (ScHARR), University of Sheffield, Sheffield, UK ${ }^{2}$ Institute of Work Psychology (IWP), Sheffield University Management School, University of Sheffield, Sheffield, UK
\end{abstract}

\section{Correspondence to} Professor Suzanne Mason, School Of Health and Related Research (ScHARR), University of Sheffield, Regent Court, 30 Regent St.

Sheffield S1 4DA, UK; s.mason@sheffield.ac.uk

Received 14 November 2014 Revised 5 June 2015 Accepted 21 June 2015 Published Online First 3 September 2015

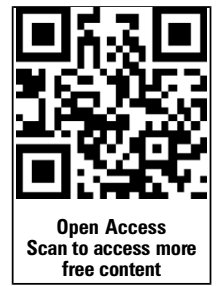

CrossMark

To cite: Mason $S$,

O'Keeffe C, Carter A, et al.

Emerg Med J 2016;33

91-98.

\section{ABSTRACT}

Objectives To measure levels of, and change in junior doctor well-being, confidence and self-reported competence over their second postgraduate training year and the impact of emergency department (ED)

placements on these outcomes.

Design A longitudinal study using an online survey administered at four time points (2010-2011).

Setting 28 Acute Hospital Trusts, drawn from nine participating Postgraduate Deaneries in England.

Participants Junior doctors who had a placement in an $E D$ as part of their second postgraduate training year. Main outcome measures Levels of anxiety, depression, motivation, job satisfaction, confidence and self-reported competence, collected at four time points spread over the period of the doctor's second training year (F2).

Results 217 junior doctors were recruited to the study. Over the year there was a significant increase in their overall job satisfaction, confidence and self-reported competence. Junior doctors also reported significantly increased levels of motivation and anxiety, and significantly decreased levels of extrinsic job satisfaction when working in ED compared with other specialties. There were also significant increases in both junior doctor confidence and self-reported competence after their placement in ED relative to other specialties. Conclusions While elements of junior doctor wellbeing worsened in their ED placement compared with their time spent in other specialties, the increased levels of anxiety and reduced extrinsic job satisfaction were within the normal range for other healthcare workers. These deficits were also balanced by greater improvements in motivation, confidence in managing common acute clinical conditions and perceived competence in performing acute procedures compared with benefits offered by placements in other specialties.

\section{BACKGROUND}

Issues of well-being (such as anxiety and depression), and confidence and competence in undertaking clinical tasks, are important considerations in postgraduate medical training. The transition from medical school to clinical practice is recognised as challenging for junior doctors in both UK and non-UK studies, with high levels of stress and depression noted. ${ }^{1-4}$ Such symptoms in junior doctors have been linked to reduced confidence in performance of clinical tasks, ${ }^{5}$ negative perceptions of work $^{6}$ and poorer quality of patient care. ${ }^{7}$ Research has also focused on junior doctors working in the emergency department (ED),

\section{Key messages}

What is already known on this subject?

- The transition from medical school to clinical practice is recognised as both difficult and stressful for junior doctors.

- Psychological distress has been linked to reduced confidence in junior doctors in the performance of clinical tasks and increased stress and depression have also been found to negatively influence doctors' perceptions of their work and quality of patient care provided.

- There have been no multicentre longitudinal studies of junior doctor experiences during their early training years.

What might this study add?

- There are significant improvements in junior doctor job satisfaction, confidence and perceived competence during their early Foundation Training years.

- During their time working in the emergency department (ED), junior doctors reported a significantly greater improvement in their motivational effort, confidence and perceived competence compared with working in any other specialty placement during the study period.

- There was some reduction in extrinsic job satisfaction and increase in anxiety levels reported during their time working in the ED compared with all other specialty placements.

demonstrating a positive impact on their confidence, ${ }^{5}$ but also resulting in higher levels of stress compared with placements in other specialties, an effect linked in a UK study to factors such as unpredictable workloads. ${ }^{8}$

A major reform of postgraduate medical training was undertaken in the UK in 2004-2005 to address perceived problems with work structure, conditions and training opportunities for junior doctors. ${ }^{9} 10$ The resultant Foundation Training (FT) programme is a 2-year postgraduate programme comprised of clinical work placements, a national curriculum with mandatory assessments of clinical competencies, and structured clinical and educational supervision. ${ }^{9}$ Junior doctors enter the 2 -year programme between qualifying at medical school and embarking on their specialty training, the structure of which varies depending on the specialty they 
pursue. However, there is no routine formal assessment of the impact that the FT has on the well-being, confidence and selfreported competence of junior doctors.

We undertook a longitudinal study to measure the levels of well-being, confidence and self-reported competence in a cohort of junior doctors in England, at key time points over the course of their second year FT, in which they received placements in three different specialties. The cohort was followed as they worked across a range of specialties, with a particular focus on their time within the specialty of emergency medicine (EM). An evaluation of FT placements showed some offered greater access to front-line decision-making and clinical care (eg, EM, acute medicine) while other placements involved routine ward-based work and less decision-making. ${ }^{11}$ As a result of this work, and the previous research cited suggesting high stress levels of junior doctors in the $\mathrm{ED},{ }^{58}$ we reasoned there was likely to be more effort and anxiety associated with the increased decision-making and unpredictable workloads identified in ED placements, but that increased clinical exposure in ED placements may also be associated with improved competence, confidence and job satisfaction for junior doctors. Specifically this study aimed to test the following hypotheses: (a) well-being measures of anxiety and depression of junior doctors would increase (ie, worsen) significantly as a result of their placement in ED in comparison to their placements in other specialties, and (b) motivational effort and job satisfaction, confidence and self-reported competence of junior doctors would show significantly greater improvement as a result of their placement in ED in comparison to their placements in other specialties.

\section{METHODS}

\section{Study design}

The longitudinal study was undertaken between July 2010 and September 2011. Data were collected from a sample of junior doctors in England, at four time points during their second year FT, using an online survey. The second year FT begins 12 months after medical school graduation and is the final year of general training before doctors select their specialty training. Each participating doctor had a placement working in ED as part of their second year FT (F2) training year. A flowchart illustrating the training structure in the UK is included in online supplementary appendix 1 .

\section{Sample size calculation}

We hypothesised that the job-related well-being of junior doctors would change over the duration of the study (four time points, $\mathrm{t} 1-\mathrm{t} 4)$. We aimed to detect a minimum of a 0.2 -unit change between $\mathrm{t} 1$ and $\mathrm{t} 4$ in anxiety-contentment scores, at the $\mathrm{p}<0.05$ level of significance, with $95 \%$ power, assuming a conservative correlation between scores of $\mathrm{r}=0.4$, and an $\mathrm{SD}$ of 0.75 (derived from published data on job-related well-being). ${ }^{12}$ We aimed to recruit 210 doctors from across at least 20 EDs. To achieve the former requirement, assuming 50\% non-response from potential participants contacted, and a further $25 \%$ loss of potential paired cases between the first and last time points, we sought to contact approximately 600 junior doctors.

\section{Recruitment of participants}

We initially contacted all 14 Postgraduate Medical Deaneries in England regarding participation in the study. Nine Deaneries consented to take part. NHS Trusts that provided a consultant-led $24 \mathrm{~h}$ ED service within those Deaneries were approached to participate. In total, 28 Trusts (containing a total of 30 EDs) agreed to take part, providing a pool of 654 eligible doctors for recruitment.

\section{Recruitment and consenting of participants}

All eligible junior doctors were emailed by their Deaneries inviting them to take part. If consenting, doctors were then contacted directly by the study team at each of the four time points.

\section{Survey methods}

An online survey, accessed via the study website, was used to collect data at each time point. The four time points at which the survey was administered-t1 (July 2010), t2 (November 2010), t3 (March 2011) and t4 (July 2011)-corresponded to the end of the doctors' first FT year (F1) placement and the ends of each of their three second FT year (F2) placements.

\section{Survey measures}

Well-being outcomes

Anxiety and depression

Two further validated three-item scales measured doctor's anxiety and depression. ${ }^{13}$ Items statements included "In the last month of your placement, how much of the time did your role make you feel worried". For each item, there were five possible response options, ranging from 1 ('not at all') to 5 ('a great deal').

\section{Motivational effort}

The survey focused on the effort that the participant would expend on their work placement. The scale was measured by three items (eg, "How would you rate the amount of effort you put into your job?"). Participants rated their effort from 1 ('lowest effort') to 5 ('greatest effort'). ${ }^{14}$

\section{Job satisfaction}

The survey incorporated a 15 -item Job Satisfaction scale ${ }^{15}$ combining subscales of intrinsic satisfaction (affective reactions to job features that are integral to the work itself; eg, variety of work) and extrinsic satisfaction (affective reactions to job features external to the work; eg, hours of work). The items explored satisfaction with areas such as the physical work conditions and freedom to choose own methods of work. There were seven possible responses ranging from 1 ('extremely dissatisfied') to 7 ('extremely satisfied'). Items relating to intrinsic satisfaction included "How satisfied are you with the amount of responsibility you are given?", and, for extrinsic satisfaction, "How satisfied were you with your rate of pay?”

\section{Confidence and self-reported competence measures}

We measured confidence and self-reported competence in the management of a selection of clinical conditions and practical procedures contained within the FT curriculum framework. ${ }^{16}$ Selection of conditions and procedures was carried out by an expert panel of acute and emergency physicians.

Participants were asked to rate their confidence in managing each of 23 common acute medical conditions (such as elderly fall, chest pain and stroke) on a nine-point scale from 1 ('lowest level of confidence') to 9 ('highest level'). The scale was adapted from a previous study of junior doctors. ${ }^{17}$

Self-reported competence in performing five acute procedures (defibrillation, ABG analysis, suturing, ECG interpretation and $\mathrm{X}$-ray interpretation) was measured. Participants were asked to rate their experience in performing each procedure, from between 1 ('no/little experience') through to 9 ('confident in performing alone'). 


\section{Quasi-experimental grouping}

Each member of the sample was categorised into one of three groups depending on whether they had completed their second postgraduate training year (F2) placement in an ED as their first, second or final placement of the year (see table 1 for ED groups). Grouping the sample in this way allowed the measurement and testing of the impact that a placement in an ED had on doctors' work-related outcomes.

\section{Demographic and background variables}

A selection of potentially confounding demographic and career characteristic variables likely to influence study outcomes were also collected from participants. Specific measures included age, gender, ethnicity, length of time qualified as a doctor and place of qualification.

\section{Analyses}

Composite scores were calculated for each of the scale measures of well-being and work-related outcomes, for each respondent at each time point, by taking the average score across the respective sets of items. Our hypotheses concerning the pattern of change over the duration of the study in well-being outcomes, confidence in managing acute medical conditions and self-reported competence performing acute procedures-and the relationships between the pattern of change in these outcomes and the timing of a respondent's ED placement-were tested using longitudinal multilevel models for each outcome. ${ }^{18}$ As such the data were arranged at the level of response time point nested within subjects (ie, one row per time point per subject), which in turn were nested within EDs, forming a three-level model.

This methodology enabled the variance in each outcome that was attributable to subjects and their EDs to be distinguished from the variation in which we were primarily interested in explaining i.e. that in scores over time within subjects. For each outcome, an autoregressive (AR1) correlation structure was also fitted to the within-subjects variance to account for the non-independence of observations over time within the same respondent. Our central question of interest, namely whether non-zero change over time had occurred, was modelled by testing the effect of time point as a predictor of each outcome, having first controlled for subject-level background variables of age, length of time qualified as a doctor (both logarithm-transformed due to the positive skew of their respective distributions), gender and ED F2 placement group (dummy coded).

Given the small number of time points, and different respondents experiencing their ED placement at different points of the year (and hence the hypothesised changes in outcomes associated with ED placement being likely to occur between differing pairs of time points), time of response was treated as a categorical variable, with the last time point (4) treated as the reference category. This enabled us to easily test both the 'headline' change over the whole year (given by the regression coefficient for the dummy variable representing the comparison of time point 1 against reference category time point 4) and also quantify the extent and pattern of change over four time points (the B-coefficients for the dummy variables and F-test of the time factor as a whole). Our hypotheses concerning variation in change over time by quasi-experimental grouping (ie, when ED placement occurred) were assessed by further entering the interaction between time point and ED group.

For all quantitative tests, two-tailed tests were used, with the $\mathrm{p}<0.05$ level of statistical significance applied. 95\% CIs for estimates are reported throughout. Where multiple related outcomes were examined, p values were Bonferroni corrected (ie, multiplied by the number of related outcome variables).

\section{RESULTS}

\section{Response rate}

We approached 28 UK trusts employing 658 junior doctors in their second postgraduate training year (F2). We recruited 217 (33\%) of these to participate in the study. In toal, 586 observations were collected across the four time points: 87 doctors completed the survey at every time point, 26 at just three time points, 56 completed at two time points and 48 completed at just one time point. Table 1 details the number of respondents at each of the four time points, and the pattern of respondents' ED placement.

\section{Response sample characteristics}

The mean age of the 217 junior doctors included in the analysis was 27 years (range 24-44 years, $S D=3.7$ ); 58.2\% were women; and their mean period of medical qualification was of 1.5 years (range 1-17 years, SD 2.1). Eighty-three per cent had completed their medical training in the UK. There were no statistically significant differences between the respondents in the three ED groups in terms of age and length of time qualified as a doctor, nor any association between group and gender.

Comparing doctors who responded only once with those who responded two times, three times or at all four time points revealed no statistically significant differences in their well-being or work-related outcomes; nor were there any consistent relationships between competency, confidence and the number of time points at which a participant responded.

\section{Change over time and variation in change in well-being outcomes}

Anxiety and depression

Junior doctors did not report statistically significant changes in either anxiety or depression across the four time points (see tables 2 and 3). However, there was a significant interaction between time point and time of working in ED when predicting mean anxiety levels. Respondents typically showed the steepest rise in mean anxiety levels during their time working in ED (figure 1).

Table 1 Respondents completing questionnaires at each time point

\begin{tabular}{|c|c|c|c|c|}
\hline $\begin{array}{l}\text { Survey time point (and corresponding F1/F2 } \\
\text { placement) }\end{array}$ & $\begin{array}{l}\mathrm{t} 1 \text { (end of final F1 } \\
\text { placement; } 01 / 04 / 10-31 / \\
07 / 10\end{array}$ & $\begin{array}{l}\text { t2 (end of 1st F2 } \\
\text { placement: } 01 / 08 / 10- \\
30 / 11 / 10\end{array}$ & $\begin{array}{l}\mathrm{t} 3 \text { (end of } 2 \mathrm{nd} \mathrm{F2} \\
\text { placement }(01 / 12 / 10- \\
31 / 03 / 11\end{array}$ & $\begin{array}{l}\text { t4 (end of final F2 } \\
\text { placement; 01/04/11-31/ } \\
07 / 11\end{array}$ \\
\hline Date intervals when survey completed & $30 / 07 / 10-26 / 10 / 10$ & $01 / 12 / 10-03 / 03 / 11$ & 20/03/11-13/06/11 & 19/07/11-24/09/11 \\
\hline $\mathrm{N}(\%)$ responding at each time point (total $=217$ ) & $188(86.6 \%)$ & $154(71.0 \%)$ & $135(62.2 \%)$ & $108(49.8 \%)$ \\
\hline $\begin{array}{l}\text { Number }(\%) \text { of respondents in emergency } \\
\text { department } \mathrm{F} 2 \text { Placement groups directly preceding } \\
\text { each time point }(\mathrm{N}=217)\end{array}$ & $\mathrm{N} / \mathrm{A}$ & $90(41.5 \%)$ & $61(28.1 \%)$ & $66(30.4 \%)$ \\
\hline
\end{tabular}


Table 2 Sample mean scores (95\% Cls) for overall well-being, motivation, confidence and self-reported competence over time by emergency department (ED) group (time of placement)

\begin{tabular}{|c|c|c|c|c|c|}
\hline ED group (timing of ED in F2 placement) & $\begin{array}{l}1 \\
\text { Mean }(95 \% \mathrm{Cl})\end{array}$ & $\begin{array}{l}2 \\
\text { Mean }(95 \% \mathrm{Cl})\end{array}$ & $\begin{array}{l}3 \\
\text { Mean }(95 \% \mathrm{Cl})\end{array}$ & $\begin{array}{l}4 \\
\text { Mean }(95 \% \mathrm{Cl})\end{array}$ & $\begin{array}{l}\text { Total } \\
\text { Mean }(95 \% \mathrm{Cl})\end{array}$ \\
\hline \multicolumn{6}{|l|}{ Group 1 (ED in 1st F2 placement) } \\
\hline Anxiety & 1.94 (1.77 to 2.11$)$ & $2.42(2.13$ to 2.70$)$ & 1.74 (1.59 to 1.90$)$ & 1.95 (1.77 to 2.14$)$ & 2.02 (1.91 to 2.13$)$ \\
\hline Depression & 1.71 (1.54 to 1.88$)$ & 1.82 (1.57 to 2.06$)$ & 1.56 (1.33 to 1.78$)$ & 1.59 (1.39 to 1.78$)$ & $1.68(1.57$ to 1.78$)$ \\
\hline Motivational effort & $4.18(4.05$ to 4.30$)$ & 4.39 (4.25 to 4.52$)$ & 3.98 (3.79 to 4.17$)$ & 4.11 (3.94 to 4.29 ) & 4.17 (4.09 to 4.25$)$ \\
\hline Job satisfaction & 4.81 (4.66 to 4.97 ) & 5.14 (4.97 to 5.32$)$ & $5.23(5.03$ to 5.43$)$ & 5.22 (4.99 to 5.44$)$ & $5.08(4.98$ to 5.17$)$ \\
\hline Extrinsic job satisfaction & $5.06(4.91$ to 5.20$)$ & $5.12(4.95$ to 5.29$)$ & 5.28 (5.08 to 5.47$)$ & 5.30 (5.09 to 5.51$)$ & $5.17(5.08$ to 5.26$)$ \\
\hline Intrinsic job satisfaction & 4.53 (4.34 to 4.73$)$ & 5.18 (4.98 to 5.38$)$ & 5.18 (4.94 to 5.42$)$ & $5.12(4.85$ to 5.39$)$ & 4.97 (4.85 to 5.08$)$ \\
\hline Medical conditions & $5.96(5.75$ to 6.17$)$ & 6.80 (6.61 to 6.99$)$ & $6.80(6.61$ to 6.98$)$ & 7.10 (6.89 to 7.32 ) & $6.60(6.48$ to 6.71$)$ \\
\hline Acute procedures & 5.80 (5.58 to 6.02$)$ & 6.87 (6.64 to 7.11$)$ & 6.35 (5.96 to 6.75$)$ & 6.99 (6.70 to 7.28$)$ & $6.44(6.29$ to 6.59$)$ \\
\hline \multicolumn{6}{|l|}{ Group 2 (ED in 2nd F2 placement) } \\
\hline Anxiety & 1.97 (1.74 to 2.20$)$ & 1.88 (1.65 to 2.11$)$ & $2.46(2.11$ to 2.80$)$ & 1.74 (1.51 to 1.97$)$ & $2.02(1.88$ to 2.15$)$ \\
\hline Depression & 1.59 (1.37 to 1.81$)$ & 1.55 (1.28 to 1.82$)$ & $1.72(1.41$ to 2.04$)$ & 1.49 (1.24 to 1.74$)$ & 1.59 (1.46 to 1.72$)$ \\
\hline Motivational effort & 4.25 (4.08 to 4.43 ) & 4.33 (4.13 to 4.52$)$ & $4.54(4.35$ to 4.74$)$ & 4.36 (4.16 to 4.56$)$ & $4.36(4.26$ to 4.45$)$ \\
\hline Job satisfaction & 4.93 (4.71 to 5.15 ) & 5.41 (5.17 to 5.64$)$ & 4.98 (4.68 to 5.27 ) & $5.40(5.19$ to 5.61$)$ & 5.15 (5.03 to 5.28$)$ \\
\hline Extrinsic job satisfaction & 5.08 (4.85 to 5.30$)$ & 5.56 (5.36 to 5.77$)$ & 5.03 (4.75 to 5.30$)$ & 5.56 (5.38 to 5.74$)$ & 5.28 (5.16 to 5.41$)$ \\
\hline Intrinsic job satisfaction & 4.76 (4.51 to 5.01$)$ & 5.23 (4.93 to 5.52 ) & 4.92 (4.58 to 5.26$)$ & 5.22 (4.91 to 5.54$)$ & 5.01 (4.86 to 5.16 ) \\
\hline Medical conditions & 6.25 (6.03 to 6.47$)$ & $6.30(6.05$ to 6.56$)$ & 7.24 (7.04 to 7.45$)$ & 7.33 (7.15 to 7.51$)$ & $6.68(6.54$ to 6.71$)$ \\
\hline Acute procedures & 5.96 (5.70 to 6.22$)$ & 6.29 (5.94 to 6.64$)$ & 7.28 (7.01 to 7.55$)$ & 7.44 (7.18 to 7.71$)$ & 6.61 (6.43 to 6.78$)$ \\
\hline \multicolumn{6}{|l|}{ Group 3 (ED in final F2 placement) } \\
\hline Anxiety & 2.15 (1.91 to 2.39$)$ & 2.42 (2.16 to 2.67 ) & 2.01 (1.76 to 2.26$)$ & 2.51 (2.11 to 2.91$)$ & 2.25 (2.11 to 2.39$)$ \\
\hline Depression & $1.66(1.43$ to 1.89$)$ & 2.00 (1.71 to 2.29$)$ & $1.63(1.40$ to 1.86$)$ & 1.92 (1.56 to 2.28$)$ & $1.79(1.65$ to 1.92$)$ \\
\hline Motivational effort & 4.21 (4.04 to 4.39 ) & 4.20 (4.04 to 4.37$)$ & 4.10 (3.88 to 4.32 ) & 4.45 (4.24 to 4.65$)$ & $4.22(4.13$ to 4.32$)$ \\
\hline Job satisfaction & 4.86 (4.65 to 5.07$)$ & 5.01 (4.70 to 5.33 ) & 5.33 (5.12 to 5.55$)$ & 5.14 (4.85 to 5.43$)$ & 5.06 (4.93 to 5.19$)$ \\
\hline Extrinsic job satisfaction & 4.96 (4.75 to 5.17$)$ & 5.16 (4.85 to 5.46$)$ & $5.39(5.17$ to 5.61$)$ & 5.12 (4.81 to 5.43$)$ & 5.14 (5.01 to 5.27$)$ \\
\hline Intrinsic job satisfaction & 4.74 (4.51 to 4.98$)$ & 4.85 (4.50 to 5.20$)$ & $5.26(5.02$ to 5.50$)$ & 5.16 (4.87 to 5.46$)$ & $4.97(4.82$ to 5.11$)$ \\
\hline Medical conditions & $6.10(5.87$ to 6.33$)$ & 6.41 (6.16 to 6.66$)$ & $6.63(6.36$ to 6.90$)$ & 7.36 (7.11 to 7.62$)$ & 6.52 (6.38 to 6.66$)$ \\
\hline Acute procedures & 5.72 (5.41 to 6.03$)$ & 5.77 (5.35 to 6.20$)$ & 5.89 (5.42 to 6.36$)$ & 7.18 (6.91 to 7.45$)$ & $6.02(5.82$ to 6.23$)$ \\
\hline \multicolumn{6}{|l|}{ Total } \\
\hline Anxiety & 2.01 (1.89 to 2.13 ) & 2.27 (2.11 to 2.43 ) & 2.01 (1.87 to 2.16 ) & 2.05 (1.89 to 2.21$)$ & 2.09 (2.01 to 2.16$)$ \\
\hline Depression & 1.66 (1.55 to 1.78$)$ & 1.80 (1.64 to 1.95$)$ & 1.62 (1.48 to 1.77$)$ & 1.65 (1.50 to 1.80$)$ & 1.69 (1.62 to 1.76$)$ \\
\hline Motivational effort & 4.21 (4.12 to 4.30 ) & 4.32 (4.22 to 4.41$)$ & 4.16 (4.04 to 4.29 ) & 4.27 (4.15 to 4.38 ) & 4.24 (4.18 to 4.29$)$ \\
\hline Job satisfaction & 4.86 (4.75 to 4.97$)$ & 5.18 (5.04 to 5.31$)$ & 5.19 (5.06 to 5.33$)$ & 5.24 (5.10 to 5.39$)$ & 5.09 (5.03 to 5.16$)$ \\
\hline Extrinsic job satisfaction & 5.03 (4.92 to 5.14$)$ & 5.25 (5.12 to 5.39$)$ & 5.25 (5.12 to 5.38$)$ & 5.32 (5.18 to 5.46$)$ & 5.19 (5.13 to 5.26$)$ \\
\hline Intrinsic job satisfaction & 4.66 (4.53 to 4.79 ) & 5.09 (4.94 to 5.25$)$ & $5.13(4.98$ to 5.29$)$ & 5.16 (4.99 to 5.33 ) & 4.98 (4.90 to 5.05$)$ \\
\hline Medical conditions & 6.08 (5.95 to 6.21$)$ & 6.54 (6.41 to 6.68$)$ & $6.86(6.73$ to 6.99$)$ & 7.23 (7.10 to 7.36$)$ & $6.60(6.52$ to 6.67$)$ \\
\hline Acute procedures & 5.82 (5.67 to 5.97$)$ & 6.38 (6.18 to 6.58$)$ & $6.45(6.20$ to 6.70$)$ & 7.16 (6.99 to 7.33 ) & 6.36 (6.26 to 6.46$)$ \\
\hline
\end{tabular}

Time point of response (mean scores and $95 \%$ Cls for pre-time and post-time points relating to ED placement are highlighted in bold text).

\section{Motivational effort}

There was no change in overall levels of motivational effort reported by doctors across the four time points of the survey (mean 4.24, SD 0.63; see tables 2 and 3). However, there was a statistically significant interaction between time point and time of working in the ED when predicting motivational effort, whereby all three ED groups showed the steepest rise in effort during their placement in the ED (see figure 2), though were likely to fall back after their next placement.

\section{Job satisfaction}

Junior doctors reported a significant increase in overall job satisfaction and intrinsic satisfaction across the four time points (see tables 2 and 4), whereas extrinsic job satisfaction was stable across the study period. However, there was a statistically significant interaction between time point and time of working in ED when predicting extrinsic job satisfaction. Two of the three ED groups (F2 placements 2 and 3) reported their steepest decline in extrinsic job satisfaction for their time in the ED compared with their other placements (see figure 3 ).

\section{Change over time and variation in change in work-related outcomes}

Confidence in managing acute medical conditions and performing acute procedures

We assessed the change in overall confidence, with overall confidence being calculated as a composite (mean) score across the 23 individual acute conditions for which competence was rated (see tables 2 and 5 for means and test statistics). Overall confidence increased significantly across the four time points, (eg, B-coefficient for $\mathrm{t} 1$ vs $\mathrm{t} 4=-1.32, \mathrm{p}<0.05$ ). There was a significant interaction between time point and time of working on a placement in ED when predicting mean overall confidence. Junior doctors were more likely to have shown their steepest increase in confidence when their immediately preceding placement had been in ED compared with immediately preceding placements in any other specialty (see figure 4). A statistically 
Table 3 Model for change over time in anxiety, depression and motivation by emergency department (ED) group

\begin{tabular}{|c|c|c|c|c|c|c|}
\hline \multirow[b]{2}{*}{ Predictor } & \multicolumn{2}{|l|}{ Anxiety } & \multicolumn{2}{|l|}{ Depression } & \multicolumn{2}{|l|}{ Motivational effort } \\
\hline & B-coefficient (95\% Cl) & $\begin{array}{l}\text { Test } \\
\text { statistic }\end{array}$ & B-coefficient $(95 \% \mathrm{Cl})$ & $\begin{array}{l}\text { Test } \\
\text { statistic }\end{array}$ & B-coefficient (95\% Cl) & $\begin{array}{l}\text { Test } \\
\text { statistic }\end{array}$ \\
\hline Gender & $-0.16(-0.35$ to 0.03$)$ & $\mathrm{t}=-1.71$ & $-0.11(-0.28$ to 0.07$)$ & $\mathrm{t}=-1.21$ & $-0.02(-0.17$ to 0.13$)$ & $t=-0.27$ \\
\hline Age (years) & $0.97^{*}(0.16$ to 1.78$)$ & $\mathrm{t}=2.36$ & $0.30(-0.46$ to 1.06$)$ & $\mathrm{t}=0.77$ & $0.54(-0.09$ to 1.17$)$ & $t=1.70$ \\
\hline Previous experience & $-0.12(-0.31$ to 0.07$)$ & $\mathrm{t}=-1.27$ & $0.03(-0.16$ to 0.21$)$ & $\mathrm{t}=0.29$ & $-0.10(-0.25$ to 0.05$)$ & $t=-1.36$ \\
\hline F2 ED placement group (overall effect) & - & $F=3.56^{*}$ & - & $\mathrm{F}=1.98$ & - & $\mathrm{F}=1.52$ \\
\hline $\begin{array}{l}\text { F2 ED placement group (dummy variable, } \\
\text { placement } 1 \text { vs } 3 \text { ) }\end{array}$ & $-0.62^{*}(-1.00$ to -0.23$)$ & $\mathrm{t}=-3.12$ & $-0.33(-0.71$ to 0.06$)$ & $\mathrm{t}=-1.66$ & $-0.25(-0.53$ to 0.03$)$ & $t=-1.79$ \\
\hline $\begin{array}{l}\text { F2 ED placement group (dummy variable, } \\
\text { placement } 2 \text { vs } 3 \text { ) }\end{array}$ & $-0.75^{*}(-1.20$ to -0.29$)$ & $t=-3.25$ & $-0.40(-0.85$ to 0.05$)$ & $t=-1.75$ & $-0.19(-0.5$ to 0.13$)$ & $t=-1.14$ \\
\hline Time (overall effect) & - & $\mathrm{F}=2.30$ & - & $\mathrm{F}=0.85$ & - & $F=1.66$ \\
\hline Time (1 vs 4$)$ & $-0.37^{*}(-0.71$ to -0.03$)$ & $t=-2.14$ & $-0.26(-0.62$ to 0.09$)$ & $\mathrm{t}=-1.48$ & $-0.22(-0.45$ to 0.02$)$ & $t=-1.82$ \\
\hline Time (2 vs 4$)$ & $-0.08(-0.42$ to 0.27$)$ & $t=-0.43$ & $0.08(-0.28$ to 0.44$)$ & $t=0.44$ & $-0.24(-0.48$ to 0.00$)$ & $t=-1.97$ \\
\hline Time (3 vs 4$)$ & $-0.54^{*}(-0.90$ to -0.18$)$ & $t=-2.92$ & $-0.29(-0.65$ to 0.07$)$ & $t=-1.59$ & $-0.32^{*}(-0.56$ to -0.08$)$ & $t=-2.62$ \\
\hline F2 ED placement group* time (overall effect) $\dagger$ & - & $F=7.56^{*}$ & - & $\mathrm{F}=1.91$ & - & $F=3.99 *$ \\
\hline
\end{tabular}

${ }^{*} p<0.05$, adjusted for multiple testing of related constructs.

tIndividual contrasts for interaction effect excluded for parsimony, effect described in the text and illustrated in figures 1 and 2.

significant interaction also existed between time point and time of working in ED when predicting the improvement in each of the 23 conditions separately. For each procedure, the steepest increase in mean confidence was most likely to follow an immediately preceding placement being in ED.

Mean overall self-reported competence (across the five different acute procedures) showed a statistically significant increase in self-reported competence over the course of the F2 year (see table 5). There was a significant interaction between time point and time of placement in ED when predicting average competence across all five acute procedures. Each group of junior doctors reported the steepest increase in self-reported
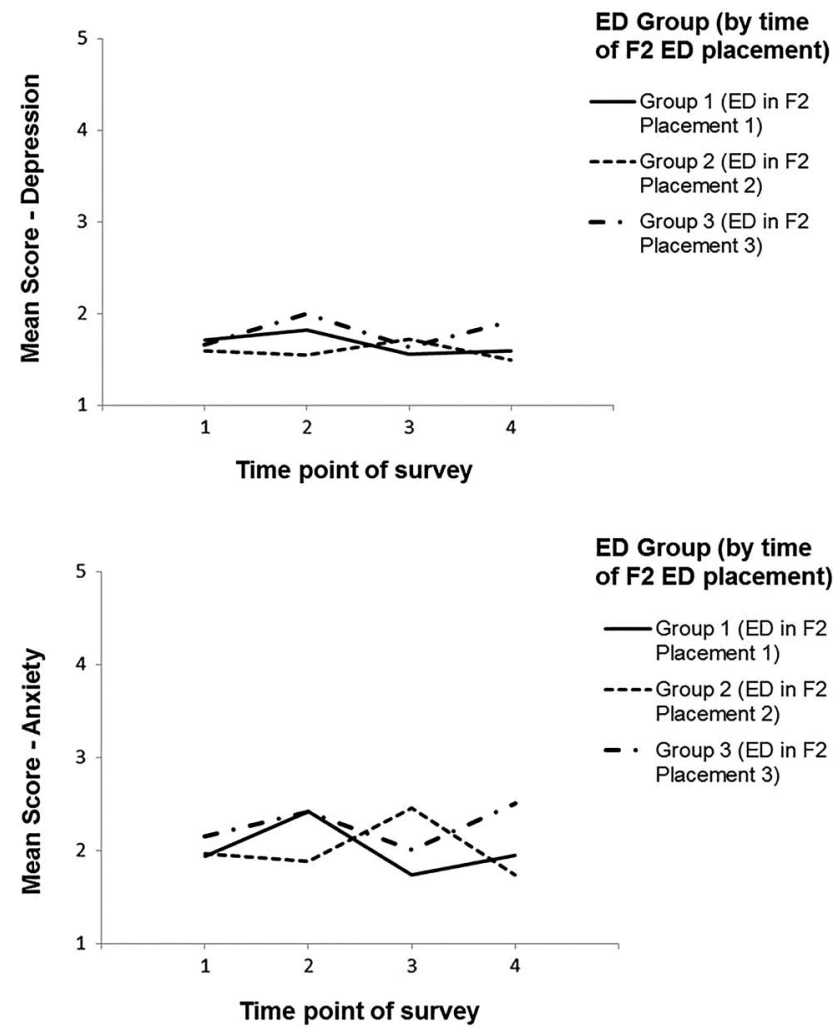

Figure 1 Interaction between time and emergency department (ED) placement for mean anxiety and depression. competence immediately following their placement working in ED compared with all other placements (see figure 4). A statistically significant interaction also existed between time point and time of working in ED when predicting the improvement in mean self-reported competence scores for four of the five procedures.

\section{DISCUSSION}

In the analysis of change in well-being across the four time points of the study, we found an increase in overall job satisfaction (and intrinsic satisfaction) of doctors over the study period, while levels of motivational effort, anxiety and depression were stable. These findings provide a more positive picture of junior doctor well-being than previous UK and non-UK studies studies, ${ }^{2} 5819$ which showed high levels of psychological distress, ${ }^{5}{ }^{8}$ depression, ${ }^{19}$ burnout and low levels of job satisfaction. ${ }^{2}$ These previous studies were undertaken before the restructuring of postgraduate training and the introduction of the European Working Directive. Our findings regarding wellbeing are consistent with another study of junior doctors from Northern Ireland, which found moderate levels of anxiety at the beginning and end of the F2 year. ${ }^{20}$ Junior doctors in our study also reported higher levels of job satisfaction than other study cohorts of doctors and NHS staff groups. ${ }^{12}$

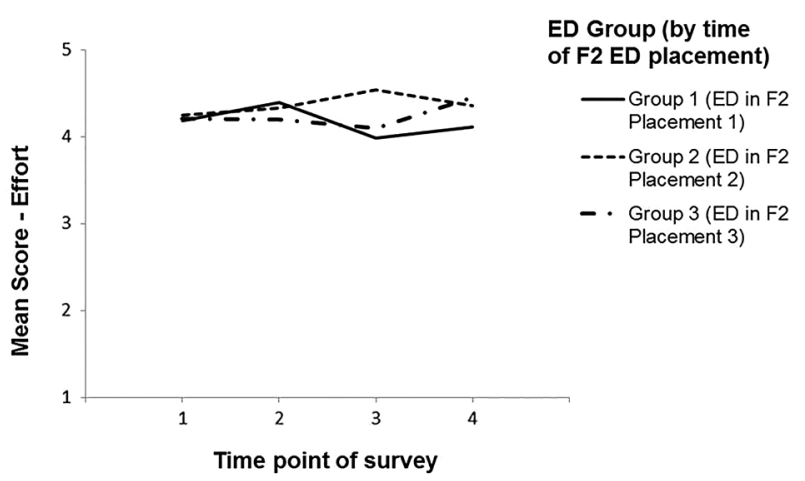

Figure 2 Interaction between time and emergency department (ED) placement for mean motivation (effort). 
Table 4 Model for change over time in job satisfaction over time by emergency department (ED) group

\begin{tabular}{|c|c|c|c|c|c|c|}
\hline \multirow[b]{2}{*}{ Predictor } & \multicolumn{2}{|l|}{ Job satisfaction } & \multicolumn{2}{|l|}{ Extrinsic satisfaction } & \multicolumn{2}{|l|}{ Intrinsic satisfaction } \\
\hline & B-coefficient $(95 \% \mathrm{CI})$ & Test statistic & B-coefficient $(95 \% \mathrm{CI})$ & Test statistic & B-coefficient (95\% CI) & Test statistic \\
\hline Gender & $0.11(-0.07$ to 0.29$)$ & $\mathrm{t}=1.20$ & $0.07(-0.10$ to 0.24$)$ & $\mathrm{t}=0.82$ & $\mathrm{t}=0.15(-0.05$ to 0.36$)$ & $t=1.50$ \\
\hline Age (years) & $-0.31(-1.09$ to 0.42$)$ & $t=-0.82$ & $-0.43(-1.17$ to 0.32$)$ & $t=-1.05$ & $\mathrm{t}=-0.22(-1.10$ to 0.63$)$ & $t=-0.51$ \\
\hline Previous experience & $-0.05(-0.23$ to 0.13$)$ & $t=-0.60$ & $-0.03(-0.20$ to 0.14$)$ & $t=-0.32$ & $\mathrm{t}=-0.08(-0.28$ to 0.13$)$ & $t=-0.74$ \\
\hline F2 ED placement group (overall effect) & - & $F=0.29$ & - & $F=0.64$ & - & $F=0.08$ \\
\hline $\begin{array}{l}\text { F2 ED placement group } \\
\text { (dummy variable, placement } 1 \text { vs } 3 \text { ) }\end{array}$ & $0.13(-0.22$ to 0.49$)$ & $\mathrm{t}=0.70$ & $0.22(-0.13$ to 0.57$)$ & $\mathrm{t}=1.19$ & $\mathrm{t}=0.04(-0.38$ to 0.46$)$ & $\mathrm{t}=0.17$ \\
\hline $\begin{array}{l}\text { F2 ED placement group } \\
\text { (dummy variable, placement } 2 \text { vs } 3 \text { ) }\end{array}$ & $0.18(-0.22$ to 0.61$)$ & $t=0.87$ & $0.38(-0.02$ to 0.79$)$ & $t=1.76$ & $t=-0.02(-0.50$ to 0.47$)$ & $\mathrm{t}=-0.08$ \\
\hline Time (overall effect) & - & $\mathrm{F}=6.33^{*}$ & - & $F=3.13$ & - & $\mathrm{F}={ }^{\star} 9.01$ \\
\hline Time (1 vs 4) & $-0.21(-0.53$ to 0.10$)$ & $t=-1.33$ & $-0.09(-0.40$ to 0.22$)$ & $t=-0.59$ & $t=-0.35(-0.72$ to 0.01$)$ & $t=-1.90$ \\
\hline Time (2 vs 4 ) & $-0.11(-0.43$ to 0.21$)$ & $t=-0.66$ & $0.05(-0.27$ to 0.36$)$ & $\mathrm{t}=0.30$ & $\mathrm{t}=-0.29(-0.66$ to 0.09$)$ & $t=-1.50$ \\
\hline Time (3 vs 4) & $0.20(-0.12$ to 0.54$)$ & $\mathrm{t}=1.23$ & $0.29(-0.03$ to 0.61$)$ & $t=1.73$ & $\mathrm{t}=0.12(-0.27$ to 0.51$)$ & $t=0.60$ \\
\hline F2 ED placement group* time (overall effect) $\dagger$ & - & $F=2.42$ & - & $\mathrm{F}=3.32^{*}$ & - & $\mathrm{F}=2.33$ \\
\hline
\end{tabular}
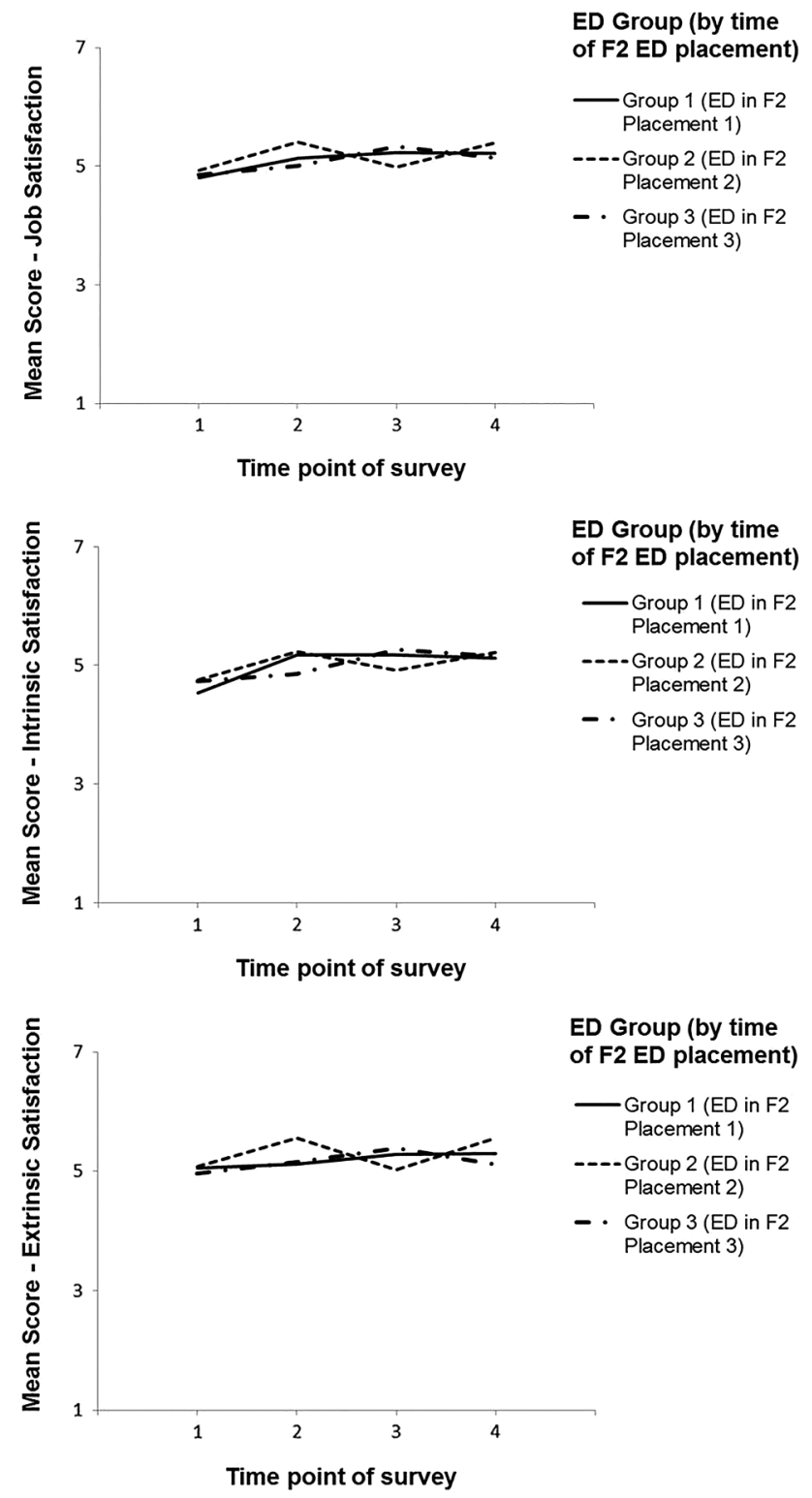

Figure 3 Interaction between time and emergency department (ED) placement for overall, intrinsic and extrinsic job satisfaction.
These stable levels of well-being and increased job satisfaction may be associated with the increased reported confidence and self-reported competence of junior doctors in our study. However, the influence of the FT programme itself is unclear given that we did not have a control sample (ie, one not receiving FT) to offer a comparison. Our findings are also based on averaged data and within cohorts of junior doctors there may be specific individuals who require additional support at specific times and/or in certain placements.

We found that participating junior doctors experienced a significant increase in both their reported overall confidence in managing common acute medical conditions and in their overall perceived competence in performing common practical
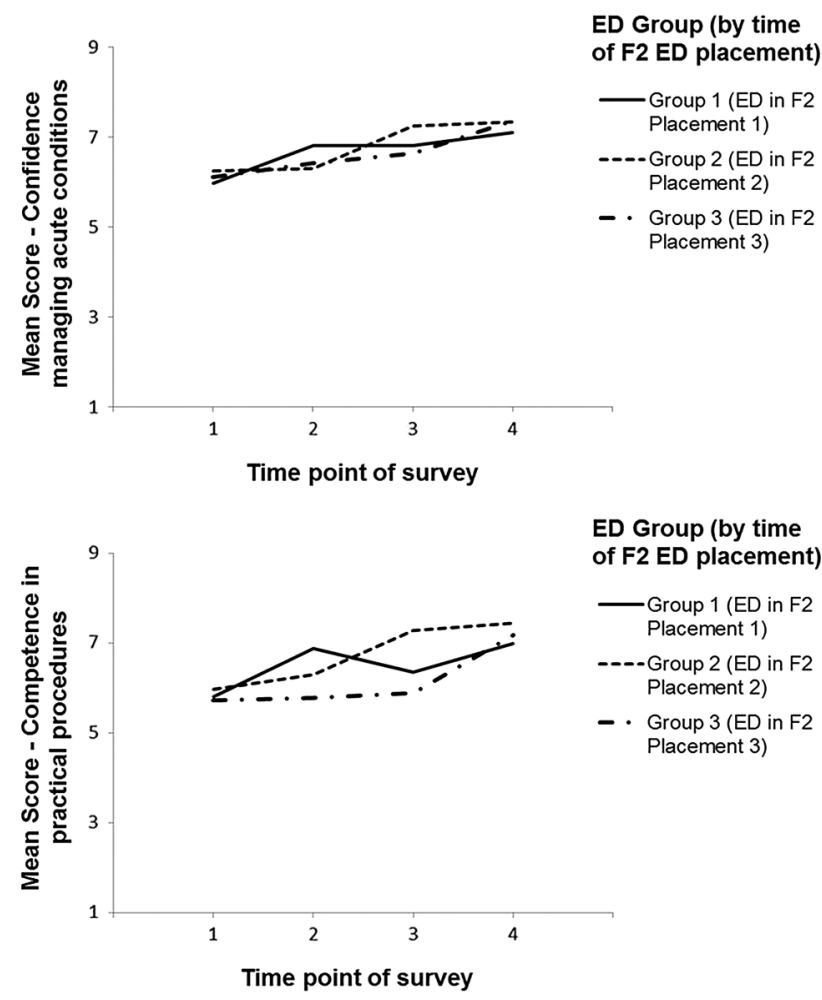

Figure 4 Interaction between time and emergency department (ED) placement for mean overall confidence and competence. 
Table 5 Model for change over time in overall confidence and self-reported competence over time by emergency department (ED) group

\begin{tabular}{|c|c|c|c|c|}
\hline \multirow[b]{2}{*}{ Predictor } & \multicolumn{2}{|l|}{ Overall confidence } & \multicolumn{2}{|c|}{ Overall self-reported competence } \\
\hline & B-coefficient $(95 \% \mathrm{Cl})$ & Test statistic & B-coefficient $(95 \% \mathrm{Cl})$ & Test statistic \\
\hline Gender & $0.02(-0.18$ to 0.23$)$ & $t=0.23$ & $0.26(-0.03$ to 0.54$)$ & $t=1.80$ \\
\hline Age (years) & $0.43(-0.46$ to 1.33$)$ & $t=0.95$ & $-0.09(-1.30$ to 1.12$)$ & $t=-0.14$ \\
\hline Previous experience & $0.05(-0.16$ to 0.25$)$ & $t=0.43$ & $0.09(-0.20$ to 0.37$)$ & $t=0.61$ \\
\hline F2 ED placement group (overall effect) & - & $F=0.76$ & - & $\mathrm{F}=6.62^{*}$ \\
\hline F2 ED placement group (dummy variable, placement 1 vs 3 ) & $-0.30(-0.65$ to 0.05$)$ & $t=-1.70$ & $-0.10(-0.59$ to 0.39$)$ & $t=-0.39$ \\
\hline F2 ED placement group (dummy variable, placement 2 vs 3 ) & $-0.06(-0.47$ to 0.34$)$ & $t=-0.30$ & $0.26(-0.31$ to 0.82$)$ & $t=0.89$ \\
\hline Time (overall effect) & - & $\mathrm{F}=81.39^{*}$ & - & $\mathrm{F}=56.80^{*}$ \\
\hline Time (1 vs 4) & $-1.32 *(-1.60$ to -1.04$)$ & $\mathrm{t}=-9.32$ & $-1.57^{*}(-1.97$ to -1.18$)$ & $\mathrm{t}=-7.83$ \\
\hline Time (2 vs 4) & $-0.99 *(-1.27$ to -0.71$)$ & $t=-6.93$ & $-1.48^{*}(-1.88$ to -1.08$)$ & $\mathrm{t}=-7.26$ \\
\hline Time (3 vs 4 ) & $-0.82^{*}(-1.09$ to -0.56$)$ & $t=-6.03$ & $-1.42^{*}(-1.83$ to -1.02$)$ & $t=-6.97$ \\
\hline F2 ED placement group* time (overall effect) $\dagger$ & - & $\mathrm{F}=7.71$ * & - & $\mathrm{F}=9.00^{*}$ \\
\hline
\end{tabular}

procedures. Our study also demonstrated that this significant increase in confidence in the management of conditions also applied to each of 23 specific conditions individually, including acute mental health problems, collapse, cardiac arrest, seizure, back pain and elderly fall. Similarly, there was significant improvement in self-reported competence in four of five acute procedures individually, which made up the overall selfreported competence measure (ie, defibrillation, suturing, ECG interpretation and radiograph interpretation). While there are limits to the conclusions about doctor's abilities that can be drawn from self-reported confidence and self-reported competence alone, there is also evidence that a subsample of this cohort of junior doctors are providing care that is of a good quality. ${ }^{11}$

We hypothesised that ED placements would have significant benefits for junior doctors (relative to other specialties) in terms of confidence and self-reported competence, but at the cost of increased effort and anxiety. Time working in the ED did indeed produce significant increases in reported confidence and self-reported competence in managing common clinical conditions and performing practical procedures in comparison with changes reported when working in all other specialties during the year. However, the ED placement was also associated with the steepest rise in levels of anxiety for junior doctors and (for two of the three ED groups) the steepest decline in extrinsic job satisfaction. Participating doctors' anxiety levels were found to be similar to those measured in a large sample of professional and technical workers. ${ }^{21}$ Reduced extrinsic satisfaction is likely to be linked to ED shift working, which has also been identified as an issue internationally. ${ }^{22}$ There was also a significant rise in motivational effort associated with working in the ED compared with other specialties. There are no studies evaluating motivation in health service populations, although the levels of effort reported by our sample of doctors was lower than reported by a group of professional managers. $^{21}$

Our findings show that ED placements at junior doctor level result in a small reduction in well-being that is within the normal range for healthcare workers, while offering a balance of increasing self-reported confidence and competence compared with other specialties. These findings are likely to be generalisable to many international EM settings with similar levels of patient activity who employ junior doctors as part of their staffing cohort.

\section{STRENGTHS AND WEAKNESSES OF STUDY}

Our study is the first to systematically examine a sample of junior doctors at the end of their first postgraduate year and throughout the second postgraduate training year. The data in this study were collected over 3 years ago (2010-2011) and since then there have been a continued increase in demand for EM services by patients, which has placed the service under increasing strain. ${ }^{23}$ These challenges are also an international issue for EM. ${ }^{24}$ Alongside these challenges, there have also been difficulties in recruitment and retention of doctors to the specialty in the UK. ${ }^{25}$ In addition, a recent report by the UK General Medical Council raised concerns that these strains on the ED were contributing to a lack of clinical supervision for doctors in training and doctors being asked to work beyond their competence in some EDs. ${ }^{26}$ These recent issues are likely to increase stress on all ED staff, including postgraduate doctors, and may mean that current doctors are at higher risk of anxiety and reduced job satisfaction than those in our study. However, we believe this study provides evidence that working within the specialty as a junior doctor is beneficial in terms of gaining confidence and competence with no significant adverse impact on anxiety levels.

Our sample of 217 junior doctors covered 9 Deaneries and 28 trusts in England. Because of confidentiality constraints, Deaneries self-selected to be part of this sample, which may preclude those that had particular difficulties in well-being and motivation. However, the study achieved its intended sample size of 210 doctors needed to address the primary outcome of the study (change in well-being over the year). The fact that these doctors were distributed over a range of EDs and NHS trusts strengthens the generalisability of the study findings. However, participants explored the information about the study and self-selected to be involved. Therefore, it is possible that the group of participants who made themselves available for this study had robust levels of well-being when joining the study. The percentage of participants completing the survey reduced between $\mathrm{t} 1$ and $\mathrm{t} 4$ from $87 \%$ to $50 \%$, although there was no evidence that dropout was related to any of the well-being or work-related outcomes, nor to any demographic properties.

\section{CONCLUSION}

Our study demonstrated that confidence of junior doctors in managing acutely ill patients and self-reported competence in carrying out practical procedures improved significantly over the 
year; with greater improvements following time in ED compared with other specialties. Levels of anxiety were significantly higher, and levels of extrinsic job satisfaction significantly lower in the ED compared with other specialties; however, these levels of anxiety and job satisfaction are within the normal range for other healthcare workers.

Acknowledgements We would like to thank the participating emergency departments and junior doctors who gave up their time to participate in this study.

Contributors SM initiated the project, designed the study and monitored the study including data collection; wrote and revised drafts of the paper and is the guarantor. CO project managed the study; designed data collection instruments; wrote and revised drafts. AC contributed to the design of the study, designed data collection instruments and revised drafts. CS contributed to the design of the study, designed data collection instruments and revised drafts.

Funding Department of Health-National Institute for Health Research-Health Services and Delivery Research (HS\&DR) Programme. HS\&DR 08/1819/221.

Competing interests None declared.

Ethics approval Leeds East Ref: 09/H1300/80.

Provenance and peer review Not commissioned; externally peer reviewed.

Open Access This is an Open Access article distributed in accordance with the Creative Commons Attribution Non Commercial (CC BY-NC 4.0) license, which permits others to distribute, remix, adapt, build upon this work non-commercially, and license their derivative works on different terms, provided the original work is properly cited and the use is non-commercial. See: http://creativecommons.org/ licenses/by-nc/4.0/

\section{REFERENCES}

1 Brennan N, Corrigan O, Allard J, et al. The transition from medical student to junior doctor: today's experiences of Tomorrow's Doctors. Med Edu 2010;44:449-8.

2 Markwell A, Wainer $Z$. The health and well-being of junior doctors: insights from a national survey. Med J Aust 2009;191:441-4.

3 Firth-Cozens J. Emotional distress in junior house officers. Br Med J (Clin Res Ed) 1987;295:533-6.

4 Whitley T, Jackson A, Gallery M, et al. Work-related stress and depression among physicians pursuing postgraduate training in emergency medicine: an international study. Ann Emerg Med 1991;20:992-6.

5 Williams S, Dale J, Glucksman E, et al. Senior house officers' work-related stressors, psychological distress, and confidence in performing clinical tasks in accident and emergency: a questionnaire study. Br Med J 1997;314:713-18.

6 Firth-Cozens J. Sources of stress in women junior house officers. $\mathrm{Br}$ Med $\mathrm{J}$ 1990;301:89-91.

7 West $P$, Huschka M, Novotny $P$, et al. Association of perceived medical errors with resident distress and empathy: a prospective longitudinal study. JAMA 2006;296:1071-8.
8 McPherson S, Hale R, Richardson P, et al. Stress and coping in accident and emergency senior house officers. Emerg Med J 2003;20:230-1.

9 Department of Health. The next steps-the Future Shape of Foundation, Specialist and General Practice. London: Department of Health, 2004.

10 Donaldson L. Unfinished business: proposals for reform of the senior house officer grade. London: Department of Health, 2002.

11 Mason S, O'Keeffe C, Carter A, et al. An evaluation of foundation doctor training: a mixed-methods study of the impact on workforce well-being and patient care [the Evaluating the Impact of Doctors in Training (EDiT) study]. Health Serv Deliv Res 2013;1(15). Southampton (UK): NIHR Journals Library; 2013 Dec. http://www. journalslibrary.nihr.ac.uk/_data/assets/pdf_file/0006/96477/FullReport-hsdr01150.pdf

12 Stride C, Wall TD, Catley N. Measures of job satisfaction, organisational commitment, mental health and job related well-being: a benchmarking manual. Chichester: John Wiley \& Sons Ltd, 2007.

13 Warr PB. Work, unemployment and mental health. Oxford: Oxford University Press, 1987.

14 Pritchard E, Ashwood EL. Managing motivation: a manager's guide to diagnosing and improving motivation. New York: LEA/Psychology Press, 2008.

15 Warr PB. The measurement of well-being and other aspects of mental health. J Occup Psychol 1990;63:193-210.

16 Academy of Medical Royal Colleges Foundation Programme Committee. Foundation Programme curriculum 2012. London: Academy of Medical Royal Colleges, 2012. http://www.foundationprogramme.nhs.uk/pages/home/curriculum-and-Assessment/ curriculum2012 (accessed 7 Aug 2013).

17 Croft SJ, Mason S. Are emergency department junior doctors becoming less experienced in performing common practical procedures? Emerg Med J 2007;24:657-8

18 Field A. Discovering Statistics using SPSS. 3rd edn. London: Sage, 2009.

19 Reuben DB. Depressive symptoms in medical house officers. Effects of level of training and work rotation. Arch Intern Med 1985;145:286-8.

20 O'Donnell M, Noad R, Boohan M, et al. Foundation programme impact on junior doctor personality and anxiety in Northern Ireland. Ulster Med J 2012;81:19-25.

21 Sevatos P, Smith L, Cordery JL. Evidence on the reliability and construct validity of Warr's (1990) well-being and mental health measures. J Occup Organ Psychol 1992;65:33-49.

22 Hoonpongsimanont W, Murphy M, Kim C, et al. Emergency medicine resident well-being: stress and satisfaction. Occup Med (Lond) 2014;64:45-8.

23 Pym H. A\&E Departments: More bad news. http://www.bbc.co.uk/news/ health-30853342 (accessed 4 Mar 2015).

24 Lowthian J, Curtis A, Cameron P, et al. Systematic review of trends in emergency department attendances: an Australian perspective. Emerg Med J 2011;28:373-7.

25 Health Education England. Emergency Medicine. Background to HEE proposals to address workforce shortages. Health Education England, 2013. http://hee.nhs.uk/ wp-content/uploads/sites/321/2013/12/EM-publication-Nov131.pdf (accessed Feb 2015).

26 General Medical Council. Medical Education's Frontline. A review of training in seven emergency departments. London: General Medical Council, 2013. 